\title{
Product vision management: concept and models evaluation
}

\author{
João Luís Guilherme Benassi, Daniel Capaldo Amaral, Lucelindo Dias Ferreira Junior \\ University of São Paulo \\ e-mails: benassi@sc.usp.br; amaral@sc.usp.br, lucelindo@usp.br
}

\begin{abstract}
The product innovation management literature indicates vision as vital for product development success, especially for the innovative ones. Scholars have recently brought this idea to the center stage due to the Agile Project Management and Innovation literature and suggested that it should be managed. However, there is a lack of operational definitions for product vision and the conception of product vision management. It is a theoretical problem and a barrier for professionals interested in putting this idea in practice. This study contributes with a definition of product vision, the conceptualization of product vision management and a systematic analysis of available product representation models, identifying their advantages and disadvantages, for product vision support. These results were found through a systematic analysis of models used in New Product Development Management and Agile Project Management literature. It examines models of functions, digital representation, product structure, and requirements. It proposes that a body of knowledge on product vision management is a key element to support innovative product development projects. The paper offers a starting point for the development of methods and models capable of solving the problem for both Agile Project Management and New Product development scholars.
\end{abstract}

Keywords: project management, new product development, product vision, product vision management, agile project management.

\section{Introduction}

In recent years, many authors have discussed the potentialities of the Agile Project Management (APM) as a possible solution to manage projects characterized by high degree of complexity and uncertainty, that is, whose solutions and goals are poorly defined early in the project (FERNANDEZ; FERNANDEZ, 2009).

APM may be defined as a set of values, principles, and practices that assist project teams in delivering valuable products or services in complex, unstable, and challenging environments. Values and principles relate to concepts whereas practices are associated with ways of accomplishing it (HIGHSMITH, 2004).

Despite its origin in the software industry, Highsmith (2004) and Chin (2004) suggest the APM in new product development when they require high levels of innovation, even when they involve hardware.

One of the main distinctions between APM and traditional project management practices is the need to develop a robust and synthetic "product vision", in the early stages of project development (CHIN, 2004; HIGHSMITH, 2004; SMITH, 2007; BENASSI; AMARAL, 2011). These authors propose the replacement of the traditionally "initiation phase" for another called "envision". The purpose of this phase would be to anticipate the final product result, identify the project community (team), and establish teamwork rules (HIGHSMITH, 2004).

The last two goals, establish teamwork rules and form a project community, is similar to proponed tasks on regular Project Management (PM) literature, on Project Scope process group and Initiation phase (PMI, 2008). The first one, however, implies a new challenge: how can a project manager anticipate the conception? It means that a project manager needs to anticipate a product project goal to show or shed light on the path to be followed by the team, in order to solve the problem. Therefore, the difference lies in generating and representing a vision of final product.

Looking for the product vision at the NPD literature, however, the concept of vision is older than APM proposed. Several authors have asserted its importance for product innovation management and speed of New Product Development (NPD) process (COOPER, 1995; BROWN; EISENHARDT, 1995; LYNN; AKGUN, 2001). In this regard, Highsmith (2004), Chin (2004), and Beck et al. (2001) advance no novelties; they reiterate former authors' assertions only to claim that a vision is of great importance in APM.

The APM literature contains models for product representation like Product Vision Box, Elevator Test Statement, Product Architecture, and Product Feature 
List, seem suitable to software development, but not to the development of non software products. The literature does not show how to create a vision for non software nor does it test models proposed by New Product Development Management (NPD) theorists for product description.

On the other hand, New Product Development Management literature offers plenty of models used in product description. Although these models can, in theory, help managers to create a product vision, they were not taken into account by APM scholars and there is no studies evaluating it in the product vision creation context. They were created to support the conceptualization phase of product development, that starts after the product vision definition.

According to this reasoning, the barrier is that authors for both literatures, NPD and APM, do not discuss in depth the difference between preparing a product vision and the well-known project scope statement practices. And there is not a theory about the Product Vision Management with concepts and models specially designed to support the professionals on use it.

This paper seeks to fill these gaps. Namely, it aims to review product vision definitions in the context of project management, detail their characteristics and differences, identify product representation models proposed by NPD scholars, and evaluate them by checking their potential and the possibility of using them to describe a product vision consistent with APM. The results form a conceptual framework of Product Vision Management that offer a starting point to develop models and methods to build a body of knowledge on this area.

The next section presents a critical description of product vision definitions proposed by APM theorists and compares them with those proposed by others in literature related to strategic planning and NDP. This discussion informs the identification of characteristics employed to evaluate the models.

\section{Product vision management}

The term "vision" has spread through literature starting from strategic planning area, in the sense of business vision. According to Kotter (1995), vision has a "transformational" character in the company and is commonly described as something that helps indicate (guide) which direction to go.

Collins and Porras (1996) claim that although successful companies may adapt strategies and practices to emerging changes, their core values and purposes are long-standing. According to these authors, this rare ability to balance continuity and change requires deliberate discipline, like the development of a vision. A vision indicates what to preserve and what to change.

Since this study, literature on change management, strategic planning, and NDP has offered a plethora of examples showing the importance of vision for new product developement (CLARK, 1989; CORDERO, 1991; MABERT; MUTH; SCHMENNER, 1992; BROWN; EISENHARDT, 1995; COOPER, 1995; RAGATZ; HANDFIELD; PETERSEN, 2002; DRÖGE; JAYARAM; VICKERY, 2004; TESSAROLO, 2007; POSKELA; MARTINSUI, 2009).

To complement the business vision description suggested by Kotter (1995), authors such as Christenson and Walker (2004) suggest that it not only have a transformational character, but also comprise a sense of "enthusiasm" and commitment among people. In this manner, a vision must represent the culture of the company as well as comply with the behavior of those who are expected to follow and communicate it. According to these authors a vision should be: a) understandable, i. e., containing the essence of project goals; b) motivational, i. e., be able of convincing and atract the stakeholders to work for it; c) reliable, i. e., consistent with values and company's vision, and stakeholders' culture; and, d) challenging and demanding, i. e., it should promote people's proactivity and be conducive to effective teamwork.

There are similarities between 'vision' on strategy literature and product vision. In NPD literature the expression was firstly defined as a balance between organizational strategies and market needs, in order to create an effective concept (BROWN; EISENHARDT, 1995). These encompass the idea of the purpose but not the motivational aspects.

The recent definitions of product vision become more similar to business strategic area. Product vision as a mixture of clarity (e.g., existence of very specific goals that provide the team with direction), support (e.g., sharing of support and targets within team), and stability (e.g., consistency of objectives over time) (LYNN; AKGÜN, 2001). All clear directions, goals, and purposes for product development by a team (CRAWFORD; DI BENEDETTO, 2003). The company's ability to set clear goals and thoroughly-planned strategies for the development process and share these goals and strategies with everyone involved (TESSAROLO, 2007). A clear statement of direction and goals of the mechanisms that allow company integration in order to rapidly develop new products (CHEN; CHANG; LIN, 2010).

APM authors as Chin (2004) and Highsmith (2004) define vision in a similar manner to the aforementioned theorists. According to Chin (2004), the purpose of a vision is to show teams the implications of diverse project alternatives. Their use of the term was probably inspired by literature on change management, strategic planning, and new product development management. Then, vision should have a succinct and team-motivating definition capable of guiding changes in the course of development.

Similar to traditional focus of scope statements, the concept of vision is broken into project vision and product 
vision in APM. As regards product vision, Highsmith (2004) defines it as an expanded description of what a given product could become. The author argues that a product vision also serves to limit its characteristics.

Reid and Brentani (2010) recently conducted a study on the integration between marketing and NDP including the concept of vision. The authors remark the paucity of research related to this concept. They demonstrate too, through structural equation modeling, that market vision as well as market vision competency (to formulate the product) offer important benefits such as positive effects on early performance for radically new, high-tech products. These findings come to complement and reinforce the claim made by other authors who argue that vision is important to save time during product development and promote project success, especially on innovative products.

It is possible to notice that there are many studies about vision importance. These studies come from different areas. In order to draw up the boundaries of this study, Figure 1, adapted from Reid and Brentani (2010), presents different levels of vision found in the literature.

The original figure from Reid and Brentani (2010) was changed to include another vision level, a component of project vision, the product vision. This delimitation can be justified by the lack of studies addressing this issue. An exception to this is the study of Lin and Luh (2009), which developed a method for creating a product vision resulting from the integration of other existing methods and models.

In the same way as the above authors and in order to consolidate the knowledge related to product vision and minimize misconceptions about terms, this paper proposes a more operational definition for it.

Product vision is a high-level description, succinct and preferably graphic, of a product that does not yet exist, for which a project will be developed. This vision may comprise the following dimensions: shape, function, events, modules and interfaces between them, requirements, and goals. It should also be capable of defining product scope and be challenging and motivating to team members.

According this definition, the term Product Vision Management is considered the project management process area, on product development projects, that include the tasks to ensure the effective product vision definition and control, using a collaborative and motivational way.

In regard of this definition of vision, what are the available models to represent it and how should it be managed? The subsequent sections describe product representation models, currently used by NPD and APM theory, and that can be used to support the Product Vision Management according the definition.

\section{Product vision models from APM literature}

In the same way that authors in the traditional project management perspective propose transcribing vision into a document known as "project scope," Highsmith (2004) and Chin (2004) argue for the use of a representation model called "project datasheet." This model may be described as a simple page that contains key business goals, product specifications, and project management information (Highsmith, 2004).

On the other hand, models employed to create and represent a product vision are:

- Product Vision Box and Elevator Test Statement: These models determine a product vision and scope and identify the project community and how the project team will work. The term "box" is employed because Highsmith (2004) suggests that teams build a product image within the space delimited by a box. In

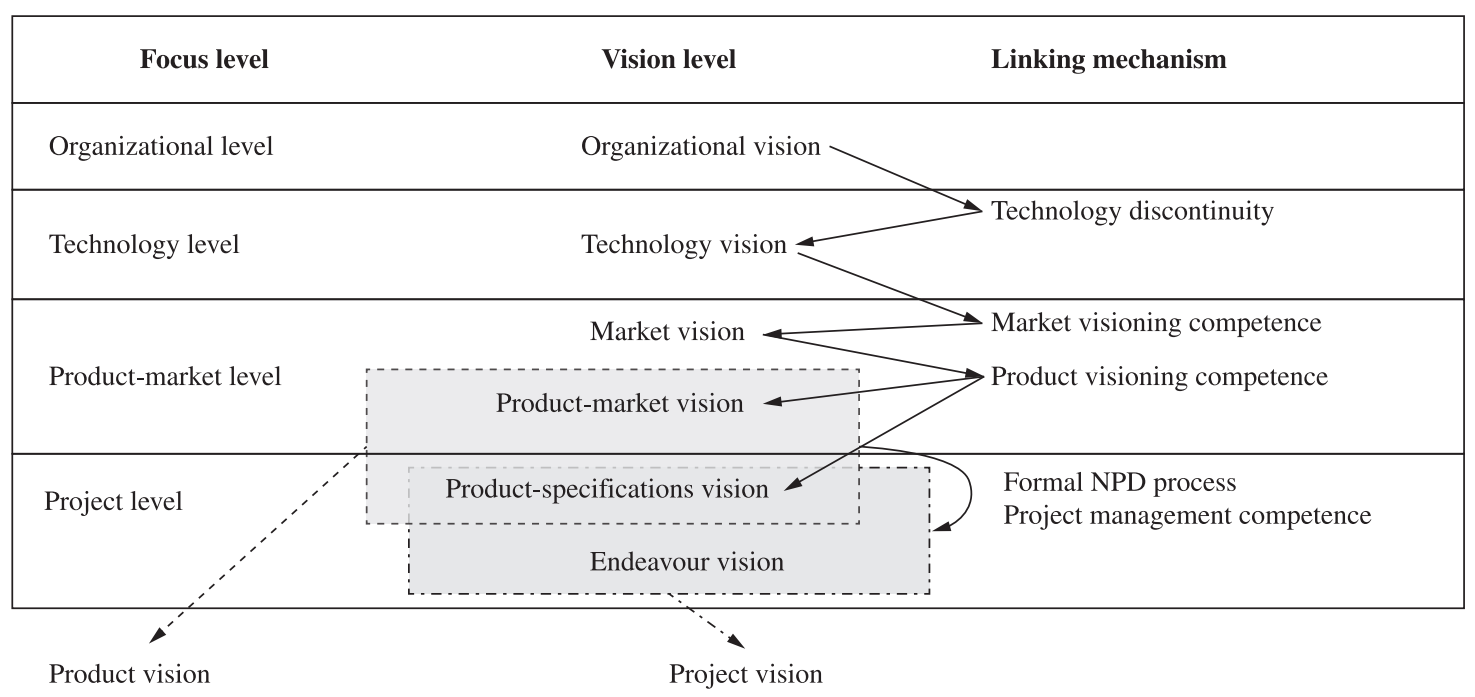

Figure 1. Levels of vision. Source: Adapted from Reid and Brentani (2010). 
turn, the Elevator Test Statement indicates that the team should position the product, i.e., it is a short statement indicating target consumers, key benefits, and competitive advantages of the product to be developed;

- Product Architecture: This model enables guiding teamwork and organizing the project team. In this model representation is carried out by Feature Breakdown Structure (FBS) to describe the product architecture. FBS consists of a list showing, by means of natural-language narrative, the SSCs (Systems, Subsystems, and Components) of a product, similar to the product structure representation model (BOM), which will be presented subsequently;

- Product Feature List: This model was conceived to expand product vision through a process of translating requirements into a list of product features. In brief, this model refines the product vision conceived in previous models. In this model the development team creates an index card for every feature identified in FBS. These index cards contain basic information and anticipated descriptive data on the product under development.

These models are based on written statements that are very similar to scope statements or project drafts proposed by traditional project management approaches. One exception is the model known as Product Vision Box, which promotes the use of visual icons to express team members' ideas. This model is more advantageous than others because the employ of visual icons (figures, pictures, designs, drafts, etc.) can foster understanding.

The next section presents product description models spread and consolidated by NPD literature. Its purpose is to verify the possibility of their use in creating a product vision in APM.

\section{Product vision models from NPD literature}

Each section below presents a model from NPD literature that can support the Product Vision Management, according the definition at section 2 . The criteria used to take them will be explained at section 5 .

\subsection{Models of representation of product functions}

Function representation models are the ones that allow us to represent a product through its features, both features through which it performs externally, i.e., in interaction with the environment, and those related to internal functions performed by its parts. These functions become an abstract formulation of the task, irrespective of any particular solution (PAHL et al., 2007).

Most authors that investigate New Product Development management (NPD) methodologies describe and recommend functional models. These authors indicate a specific method known as Function Analysis System Technique - FAST, conceived by Charles W. Bytheway in 1963 to define, analyze, and understand product features and how they relate. The result is a representation model, i.e., a diagram representing the functions of a product and their interrelations. Chief NPD authors, including Pahl et al. (2007), use FAST when it comes to describing functions, there being no records of other techniques to this end. Therefore, functional modeling and FAST are currently blurred into one.

Other studies, as Nilsson and Fagerström (2006) and Stone and McAdams (2004), also show that there are no changes in the method itself. What authors largely do is to expand its use to areas such as management of stakeholders' requirements in product modeling systems and development of a conceptual method for Design for Assembly (DFA).

\subsection{Models of digital product representation}

According Fuh and Li (2004), digital representations are product descriptions in technical design language, created by Computer-Aided Design (CAD) tools. These computational tools are used in New Product Development and project optimization and aim to assist users in specification, modeling, visualization, and simulation of products.

CAD tools can generate three-dimensional (3D) or two-dimensional (2D) designs. The transition to the $3 \mathrm{D}$ version has been beneficial in many ways, such as ease of understanding and greater agility in development. One of the limitations of 2D representation is information processing. There is the possibility that important details are not effectively communicated by designers or wrongly understood by users. On the other hand, the possibility of error in 3D representation is smaller, since its format is more intuitive and closer to reality. In addition, software programs allow for partial analysis at any time, through cuts, plans, and elevations of representations without having to consult with their designers. Another advantage is the ease with which users can store and retrieve information.

Nowadays the evolution of CAD tools occurs especially with respect to the generation of integrated environments, where there is the possibility of grouping the maximum amount of knowledge throughout every project phase (ROUCOULES; TICHKIEWITCH, 2000). According to Hartmann et al. (2003), this is possible because tasks are interrelated within a project. Thus, data communication and sharing become an important issue for the good development of activities.

The creation of integrated environments, in addition to encouraging team members to share their views with co-members, aims to decrease time spent in meetings that resort only to printed information, e.g., designs and graphs (LISTON; FISCHER; KUNZ, 2000). 
Other important CAD advances, regarding technical improvements in surface modeling, may be found in the studies of Savchenco (2005) and Fuh and Li (2004), which address collaborative projects. Finally, it is possible to verify that $\mathrm{CAD}$ tools can provide a means for creating exceptional product visions, especially $3 \mathrm{D}$ modeling as it allows the accurate description of very complex ideas.

\subsection{Models of product structure representation}

According to APICS (The Association for Operation Management), a Bill of Material (BOM) is defined as a list of all subassemblies, intermediate components, raw materials, and purchased items, employed in the manufacturing and/or assembly of a product, indicating precedence relationships and quantities of all needed items.

A BOM may contain other information such as material specifications, price, work instructions, and decisions such as "make or buy". The BOM can impart a common product vision to project members. This vision may be achieved through traceability of products, items, and components, and sharing of information among diverse departments of a company.

Most recent studies are variations of BOM. For instance, Bertrand, Zuijderwijk, and Hegge (2000) developed a modular BOM variation called hierarchical pseudo-item $\mathrm{BOM}$, that is a equivalent to a generic BOM and may be used to check the availability of materials, to allocate them according to customer needs, and to replace them in stock. On the other hand, Wacker and Miller (2000) examined a classical BOM in ETO (Engineer-To-Order) environment planning.

Finally, a BOM may be considered a promising model in the task of supporting the creation of a product vision as it represents the product through its components and their interrelationships.

\subsection{Models of representation of product requirements}

According to Pugh (1995), all design work begins with a need. The author argues that this statement of needs should be put into words, i.e., in textual form, in a model called Product Design Specification (PDS). PDS is a textual document, like a requirements statement, and operates to control design activities because they limit the scope of team members' practice throughout the development process.

The requirements statement should be unambiguous and easily understood. According to Pugh (1995), the absence of these characteristics in a requirements statement may lead to product failure. Thus, the final requirements document should contain, besides customer needs deployed into technical requirements, information such as description of elements that must be considered in its evolution and classification parameters of the product, usually guided by similar products.
When the requirements statement is compared to other documents, such as the project datasheet proposed by APM theorists, it is possible to note that they use narratives in natural language. Narratives in natural language are widely employed in new product development management and have different uses in APM.

Akao (2004) summarizes the stance of QFD (Quality Function Deployment) authors that advance an important concept related to requirements, i.e., the concept of "customer needs." According to this author, needs are original information obtained through meetings with customers. Therefore, there is a difference between this type of information and requirements, which consist of information from a more technical and structured perspective.

This more technical language, originated in customer needs, is employed to measure dimensions of the product to be developed. Thus, a requirements statement provides the development team with both focus and boundaries, which will guide entire project. This transformation of needs into product requirements is of utmost importance for organizational development in general (BAILETTI; LITVA, 1995).

In another study, Karlsson, Nellore, and Soderquist (1998) discuss the specification of requirements by manufacturers and suppliers. The specification process employed in this case could be depicted as the "black box" of engineering. According to these authors, this concept redefines the role of specification. Instead of an unchanging document that dictates what suppliers can or should do, specification functions as a conduit for communication of functional requirements, expected performance, and required technical adjustments.

This concept is similar to that of interfaces suggested by Highsmith (2004) and Chin (2004). In this concept, interfaces provide the development team with boundaries concerning the product component it is in charge of. Thus, employing this concept in requirements modeling could, in theory, benefit this model through the specification of interfaces to support the creation of a product vision.

Finally, it should be observed that the representation of requirements is an important factor for a product vision given that it faithfully mirrors needs expressed by customers in the early stages of the project. The following section presents the methodology and the research employed used in this study.

\section{Methodology and research phases}

The research method employed in this study comprised a literature review with the following phases:

- Phase 1: Literature review about vision, project management, and agile project management.

- Phase 2: Identification of classic NPD studies that 
propose models capable of describing or modeling products. The references employed to identify models are in the subsequent section.

- Phase 3: Criteria identification to qualify a representation model as valid for vision description (acceptance criteria). The criteria were developed in accordance with product vision features as described in Section 2. In order to be analyzed and evaluated, representation models had to fulfill at least one (1) of the criteria depicted in the following section. The analysis summary is shown in Table 1.

- Phase 4: Criteria identification to evaluate vision description models with respect to needs in APM. These criteria were obtained from literature on company modeling, which will be further explained in Section 6.2.

- Phase 5: Models evaluation according to criteria identified in Phase 3. This evaluation is conducted by attributing them scores according to the degree to which each criterion is fulfilled (see Table 2).

- Phase 6: Discussion of potential application of each model identified in the literature. This discussion, presented in Section 7 and based on the final scores of models, addresses their advantages and disadvantages.

The following section details the results in accordance with the order of the abovementioned phases.

\section{Analysis and results}

\subsection{Identification of models for evaluation}

The search for models to represent products originated in seminal NPD texts. Among them, there may be mentioned the studies by Bytheway (1962; 1992), Pahl et al. (2007), Guess (1985), Clark (1989), Clark and Fujimoto (1991), Pugh (1995), Akao (2004), Clausing (1994), and Baxter (1995).

From the definition of vision adopted by this study and the review of literature about vision, a more precise set of product vision features was deduced. These features, called "acceptance criteria," were taken into account when considering whether or not to accept/refuse for evaluation a given representation model. A model should:

1) Represent the product in at least one (1) of its dimensions.

2) Make the product visible through its functions.

3) Allow the description of parts (i.e., subsystems, components, and modules) and interfaces as well as their interactions in order to make work coordination easy.

4) Promote users' understanding of product.

5) Enable fast and easy visualization of main product parts as systems, subsystems, components, modules, and platform.

6) Allow the use of a language common to all users.

7) Allow description to be rapidly conducted (approximately one day for low-complexity projects).

8) Allow interaction among project team members.

In the first phase several models were identified in the texts. To this end the set of criteria presented above was used to qualify a model as being capable of assisting vision. Table 1 shows the classification of representation models, according to whether or not each abovementioned acceptance criterion was met.

\subsection{Definition of models evaluation criteria}

The models evaluation began after models selection. The researchers, therefore, looked for a new criteria group, capable to evaluate the performance of models on product vision modeling task. A distinct perspective as compared with the vision characteristics compliance (verified with acceptance criteria).

The business modeling knowledge helps to solve this issue. This area involves techniques capable of describing an organization and its operation. It is a theory in which various methods and models have been developed and described, containing several principles that allow this kind of comparison and evaluation. These models are also

Table 1. Analysis of representation models according to acceptance criteria.

\begin{tabular}{|c|c|c|c|c|}
\hline \multirow{2}{*}{$\begin{array}{c}\text { Acceptance } \\
\text { criteria }\end{array}$} & Functional & Digital representation & Product structure & Requirements \\
\cline { 2 - 5 } & Yes & Yes & Yes & No \\
\hline 1 & Yes & Yes & Yes & Yes \\
\hline 2 & Yes & Yes & Yes & Yes \\
\hline 3 & Yes & No & Yes & No \\
\hline 4 & Yes & No & Yes & Yes \\
\hline 5 & Yes & No & Yes & Yes \\
\hline 6 & No & Yes & Yes & Yes \\
\hline 7 & Yes & No & & Nos \\
\hline 8 & & &
\end{tabular}


Table 2. Evaluation of representation models according to modeling principles.

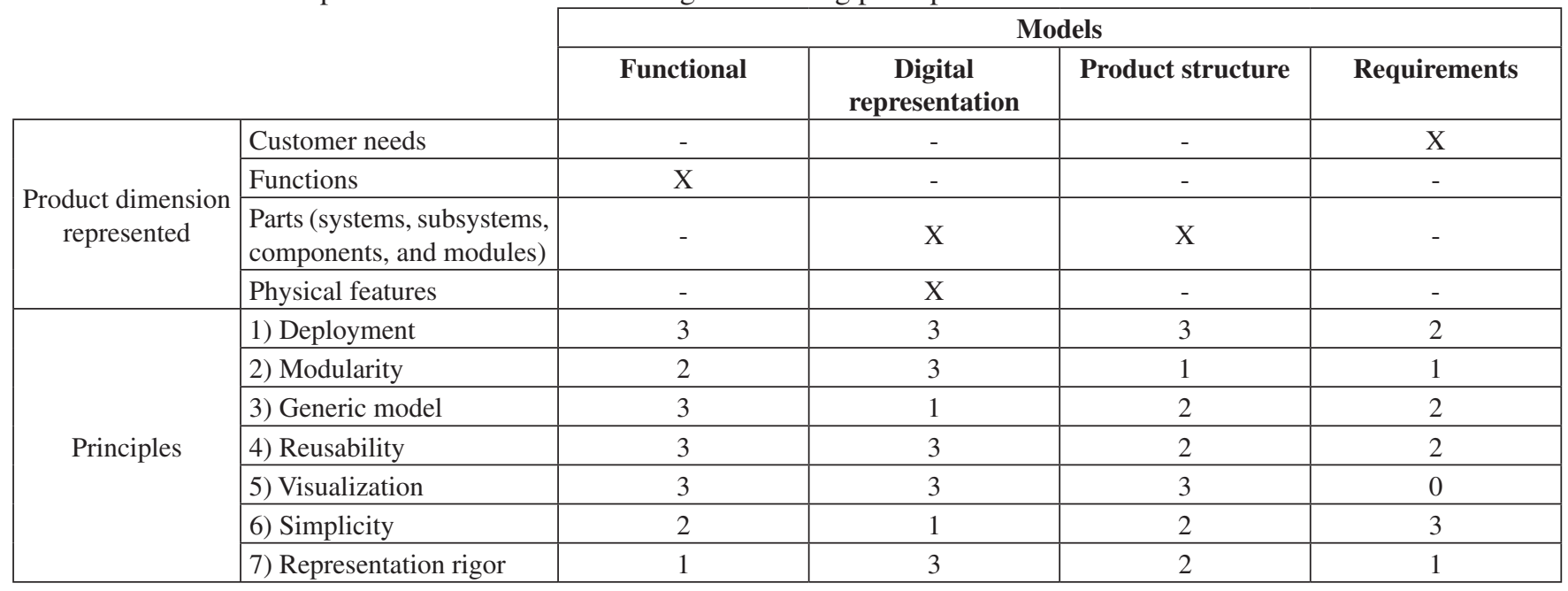

complex and very similar to product vision description. We opted for comparing business modeling principles to product modeling principles in order to obtain parameters with which to evaluate the product description models.

The study of Vernadat (1996) advances eight business modeling principles in addition to the five principles proposed by Ward and Mellor (1985). Due to space limitation the principles presented by the authors cannot be described in full in this study. This study only presents evaluation criteria and models that were adapted to the context of this investigation. These principles are:

1) Deployment Principle, the capacity of the model to break the product into smaller parts.

2) Modularity Principle, the capacity of the model to divide the product into modules, i.e., to identify parts with well-defined interfaces.

3) Generalization Principle, although a company usually manufactures different products, their conception may be often similar. Thus, the model can have a generic basis for product deployment and allow for adaptations according to product demand.

4) Reusability Principle, in order to make modeling easier and improve the modularity of the system, partial models should be reused.

5) Visual Communication Principle, in order to promote communication, modeling should be based on a simple and unambiguous model.

6) Simplicity Principle, models should be simple, i.e., use the smallest number of constructs and rules.

7) Representation Rigor Principle, the model should be neither ambiguous nor repetitive and should support verification of features, analyze behaviors, and be able to reproduce the system in question.

Table 2 presents the evaluation summary according to the abovementioned principles. It is possible to observe that this evaluation was conducted with respect to every representation dimension that models are capable of encompassing. The representation dimensions under consideration are: customer needs, functions, parts (SSCs), and physical features.

Also with regard to modeling principles, scores were assigned to each representation model. Scores range from 0 to 3 , where: $0=$ does not meet principle, $1=$ meets principle superficially, $2=$ meets principle reasonably, and $3=$ meets principle entirely.

The next sections present the evaluation results. These sections also present explanations to the attribution of each score as well as the implications of employing models to represent a product vision in APM.

\section{Evaluation results}

\subsection{Models of product functions representation}

Functional models have great potential in supporting the creation of a product vision, when comparing Principles 1 , 3,4 , and 5. This feature allows product deployment related to functionality, which may be considered a vital aspect for professionals involved in creating solutions. It also allows representing hierarchical relationships, i.e., inter-relations among product functions. As to Principle 2, despite the fact that functions identification promotes the deployment of a product into parts, this model does not allow the description of interfaces among them, which could, according to APM scholars, greatly contribute to constructing a product vision.

Upon analysis of Principle 6, this model was assigned a " 2 " because it implies, theoretically, the possibility of those involved using the same constructs. However, a team must be staffed by people knowledgeable in functional deployment and capable of employing the technique that generates the model. Finally, the least observed in this model 
was Principle 7. This is so because the model functions at a high level of abstraction, being impossible to accurately verify or simulate the model generated.

\subsection{Models of digital product representation}

The main advantage of digital representation models consists of functionalities for the tasks of designing, visualization, and reutilization of pre-existing models. This model is one that best meets Principles 1, 2, 4, 5, and 7 in addition to including the dimensions "parts" or "physical features." This model stands out when it comes to Principle 7 because, in view of 3D model representation, it is possible to describe a product thoroughly by eliminating all ambiguities. The major problem lies exactly in the level of detail that can be generated. It compromises simplicity. Many details are needed to create a representation, which makes it impossible to describe a product in a more generic or abstract way. Thus, the required knowledge about the product to be developed at this stage of the project is still not enough to build models, which consists of a trade-off.

Another aspect is that tools supporting the construction of digital designs are rather complex. This complexity can bring problems to project team members not familiar with these tools.

This problem could be circumvented by teaching those involved in creating a product vision how to use designs in a faster way. However, this ability to manipulate models can vary from person to person, which may take more time than is available in the initial phase of the project. Another problem is the use of technical language (Principle 6) in designs, which can hinder the grasping of more abstract concepts.

\subsection{Models of product structure representation}

With regard to product structure models, one can see that the best met principles are deployment (Principle 1 and Dimension "parts") and visualization (Principle 5) of the product through its systems, subsystems, and components. However, these models can become quite complex with respect to products comprising many components, which explains why this model was assigned a " 2 " as regards simplicity (Principle 6).

Another negative aspect is that it does not take into account component functionalities or interfaces between them: important and desirable features (Principle 2). Thus, information recording can assist in constructing a product vision; however, further study is needed to determine how this information should be entered and be made available so that models are not visually incomprehensible (Principle 5). This study also identifies what level of detail and what kind of information should be entered in diagrams in order to provide only the information that is necessary at a given development stage.

\subsection{Models of product requirements representation}

Requirements models have the advantage of being the simplest means of product representation studied in this paper. It only takes a construct (requirement) and a few rules to build it. However, this model only allows the use of narratives in natural language, which has a negative effect on representation accuracy (Principle 7).

The other principles were only reasonably met for the same reason, i.e., description exclusively in natural language. It should also be remarked that it lacks graphical representation, thus getting a " 0 " for this Principle, which is fundamental to obtaining a vision, according to APM. On the other hand, an important advantage of this model is that it is the only one among those analyzed that allows us to represent customer wants or needs. In short, it may be necessary to use this model jointly with other ones in order to make up for its weaknesses.

\section{Final remarks}

The scores shown in Table 2 suggest that functional and digital representation models have a slight advantage over others. They are similar in terms of meeting principles. The main difference between them is that the functional model adheres to a more abstract dimension than the digital representation model. The remaining models had significant scores on important principles such as simplicity and visualization. It is important to remark that the models herein studied seem to complement each other and that there is a shortage of research on methods to generate a more comprehensive model, one that combines those capabilities of existing models that can, hypothetically, benefit from the creation of a product vision in APM.

Therefore, further investigation of these representation models existing is called for. This evaluation should aim at verifying the potential of models in the construction of a method capable of generating a sounder product vision and to support the management process of this vision. The first option seems to combine these existents models and fill the gap existent between them.

In addition, future application of a method to generate and represent a product vision would bring empirical results to a field of knowledge lacking more robust evidence of validity of methods and models in the development of physical products.

In conclusion, this study proposes the systematization of knowledge in the field of Product Vision Management as a key element in managing product development projects, offering a starting point for developing methods and models capable of solving the product vision problem for both innovation theorists and APM researchers. 


\section{References}

AKAO, Y. Quality Function Deployment: integrating customer requirements into product design. New York: Productivity Press, 2004.

BAILETTI, A. J.; LITVA, P. F. Integrating customer requirements into product designs. The Journal of Product Innovation Management, v. 12, n. 1, p. 3-15, 1995. http://dx.doi.org/10.1016/0737-6782(94)00021-7

BAXTER, M. Product Design: a practical guide to systematic methods of new product development. London: Chapman \& Hall, 1995.

BECK, K. et al. Manifesto for agile software development. 2001. Available from: <http://www.agilemanifesto.org/>. Access in: 5 june 2011.

BENASSI, J. L. G.; AMARAL, D. C. Método para a descrição da visão do produto no contexto do gerenciamento ágil de projetos. Revista Produção, v. 21, n. 3, p. 392-403, 2011. http://dx.doi.org/10.1590/S0103-65132011005000042

BERTRAND, J. W. M.; ZUIJDERWIJK, M.; HEGGE, H. M. H. Using hierarchical pseudo bills of material for customer order acceptance and optimal material replenishment in assemble to order manufacturing of non-modular products. International Journal of Production Economics, v. 66, n. 2, p. 171-184, 2000. http://dx.doi.org/10.1016/S09255273(99)00121-8

BROWN, S. L.; EISENHARDT, K. M. Product development: past research, present findings, and future directions. Academy of Management Review, v. 20, n. 2, p. 343$378,1995$.

BYTHEWAY, C. W. FAST: an organized stimulus to applied creativity. 1962. Available from: <http://wendt.library.wisc. edu/miles/ve_studies/vecwfas.pdf $>$. Access in: 23 jan. 2008.

BYTHEWAY, C. W. FAST: an intuitive thinking technique. In: INTERNATION CONFERENCE OF THE SOCIETY OF AMERICAN VALUE ENGINEERS, 32., 1992, Phoenix. Proceedings... Phoenix: SAVE, 1992.

CHEN, C. H.; CHANG, Y. Y.; LIN, M. J. J. The performance impact of post-M\&A interdepartmental integration: An empirical analysis. Industrial Marketing Management, v. 39, n. 7, p. 1150-1161, 2010. http://dx.doi.org/10.1016/j. indmarman.2009.12.002

CHIN, G. Agile Project Management: how to succeed in the face of changing project requirements. New York: Amacon, 2004.

CHRISTENSON, D.; WALKER, D. H. T. Understanding the role of "vision" in project success. Project Management Journal, v. 35, n. 3, p. 39-52, 2004.

CLARK, K. B. Project scope and project performance: the effect of parts strategy and supplier involvement on product development. Management Science, v. 35, n. 10, p. 1247-1263, 1989. http://dx.doi.org/10.1287/ mnsc. 35.10 .1247

CLARK, K. B.; FUJIMOTO, T. Product development performance. Boston: Harvard Business School Press, 1991.

CLAUSING, D. Total quality development: a step-by-step guide to world class concurrent engineering. New York: ASME Press, 1994.

COLLINS, J. C.; PORRAS, J. I. Building your company's vision. Harvard Business Review, v. 74, n. 5, p. 66-77, 1996.

COOPER, R. G. Developing new products on time, in time. Research-Technology Management, v. 38, n. 5, p. 49-57, 1995.

CORDERO, R. Managing for speed to avoid product obsolescence: a survey of techniques. Journal of Product Innovation Management, v. 8, n. 4, p. 283-294, 1991. http://dx.doi.org/10.1016/0737-6782(91)90049-5

CRAWFORD, C. M.; DI BENEDETTO, C. A. New Products Management. 7th ed. Boston: McGraw-Hill, 2003.

DRÖGE, C.; JAYARAM, J.; VICKERY, S. K. The effects of internal versus external integration practices on time-based performance and overall firm performance. Journal of Operations Management, v. 22, n. 6, p. 557-573, 2004. http://dx.doi.org/10.1016/j.jom.2004.08.001

FERNANDEZ, D. J.; FERNANDEZ, J. D. Agile Project management: agilism versus traditional approaches. The Journal of Computer Information Systems, v. 49, n. 2, p. 10-17, 2009.

FUH, J. Y. H.; LI, W. D. Advances in collaborative CAD: stateof-the-art. Computer Aided Design, v. 37, n. 5, p. 571-581, 2004. http://dx.doi.org/10.1016/j.cad.2004.08.005

GUESS, V. C. APICS training aid: bills of material. Falls Church: American Production and Inventory Control Society, 1985.

HARTMANN, T. et al. Integration of three dimensional CAD environment into an interactive workspace. 2003. Available from: <http://cife.stanford.edu/online. publications/TR146.pdf>. Access in: 20 feb. 2008.

HIGHSMith, J. Agile Project Management: creating innovative products. Boston: Addison-Wesley, 2004.

KARLSSON, C.; NELLORE, R.; SÖDERQUIST, K. Black Box Engineering: redefining the role of product specifications. The Journal of Product Innovation Management, v. 15, n. 6, p. 534-549, 1998. http://dx.doi. org/10.1016/S0737-6782(98)00029-0

KOTTER, J. P. Leading change: why transformation efforts fail. Harvard Business Review, v. 73, n. 2, p. 59-67, 1995. 
LIN, C. C.; LUH, D. B. A vision-oriented approach for innovative product design. Advanced Engineering Informatics, v. 23, n. 2, p. 191-200, 2009. http://dx.doi. org/10.1016/j.aei.2008.10.005

LISTON, K.; FISCHER, M.; KUNZ, J. Requirements and benefits of interactive workspaces in construction. In: INTERNATIONAL CONFERENCE ON COMPUTING IN CIVIL AND BUILDING ENGINEERING, 8., 2000, Palo Alto. Proceedings... Palo Alto: ASCE, 2000. p. 1277-1284.

LYNN, G. S.; AKGÜN, A. E. Project visioning: its components and impact on new product success. The Journal of Product Innovation Management, v. 18, n. 6, p. 374-387, 2001. http://dx.doi.org/10.1016/S0737-6782(01)00110-2

MABERT, V. A.; MUTH, J. F.; SCHMENNER, R. W. Collapsing new product development times: six case studies. Journal of Product Innovation Management, v. 9, n. 3, p. 200-212, 1992. http://dx.doi.org/10.1016/07376782(92)90030-G

NILSSON, P.; FAGERSTRÖM, B. Managing stakeholder requirements in a product modelling system. Computers in Industry, v. 27, n. 2, p. 167-177, 2006. http://dx.doi. org/10.1016/j.compind.2005.06.003

PAHL, G. et al. Engineering design: a systematic approach. 3th ed. London: Springer, 2007.

POSKELA, J.; MARTINSUI, M. Management control and strategic renewal in the front end of innovation. Journal of Product Innovation Management, v. 26, n. 6, p. 671-684, 2009. http://dx.doi.org/10.1111/j.15405885.2009.00692.x

PROJECT MANAGEMENT INSTITUTE - PMI. Project Management Body of Knowledge - PMBOK: A guide to the project management body of knowledge (PMBOK guide). 4th ed. Pennsylvania: Project Management Institute, 2008.

PUGH, S. Total design: integrated methods for successful product engineering. Boston: Addison-Wesley, 1995.
RAGATZ, G. L.; HANDFIELD, R. B.; PETERSEN, K.J. Benefits associated with supplier integration into new product development under conditions of technology uncertainty. Journal of Business Research, v. 55, n. 5, p. 389-400, 2002. http://dx.doi.org/10.1016/S01482963(00)00158-2

REID, S. E.; BRENTANI, U. Market vision and market visioning competence: impact on early performance for radically new, high-tech products. Journal of Product Innovation Management, v. 27, n. 4, p. 500-518, 2010. http://dx.doi.org/10.1111/j.1540-5885.2010.00732.x

ROUCOULES, L.; TICHKIEWITCH, S. CoDE: a Cooperative Design Environment. A new generation of CAD systems. Concurrent Engineering, v. 8, n. 4, p. 263-280, 2000.

SAVCHENCO, V. Trends and solutions in CAD/CG. JSME International Journal, v. 48, n. 2, p. 184-196, 2005. http://dx.doi.org/10.1299/jsmec.48.184

SMITH, G. P. Flexible product development: building agility for changing markets. San Francisco: Jossey-Bass, 2007.

STONE, R. B.; McADANS, D. A. A product architecturebased conceptual DFA technique. Design Studies, v. 25, n. 3, p. 301-325, 2004. http://dx.doi.org/10.1016/j. destud.2003.09.001

TESSAROLO, P. Is integration enough for fast product development? an empirical investigation of the contextual effects of product vision. International Journal of Product Innovation Management, v. 24, n. 1, p. 69-82, 2007. http://dx.doi.org/10.1111/j.1540-5885.2006.00233.x

VERNADAT, F. B. Enterprising modeling and integration: principles and applications. London: Chapman \& Hall, 1996.

WACKER, J. G.; MILLER, M. Configure-to-order planning bills of material: simplifying a complex product structure for manufacturing planning and control. Production and Inventory Management Journal, v. 41, n. 2, p. 21-26, 2000 .

WARD, P. T.; MELLOR, S. J. Structured development for real-time systems. New Jersey: Prentice-Hall, 1985. 